\title{
〔61〕アクリル酸アミドの転移重合に及ぼす 触媒および溶媒の影響
}

\author{
(1963 年 1 月 11 日受理)
}

岡村誠三*・東村敏延*・妹尾忠雄 ${ }^{* *}$

\begin{abstract}
要 旨 第 I, II, III 族の金属アルコキシド，有機マグネシウムおよび亜鉛八ロゲン化物を触媒とし て, $100^{\circ} \mathrm{C}$ 付近でラジカル重合禁止剤の存在下でアクリル酸アミドの重合を行なった。一般的な傾向として は金属の塩基性の大き触媒の存在では水素転移重合によって poly- $\beta$-alanine を生成するが, 塩基性の弱 、触媒の存在下ではビニル重合も進行することが認められた。後者の場合，たとえば $\mathrm{Mg}(\mathrm{OR})_{2}$ では溶媒の 種類拉よび直換基 $\mathrm{R}$ の種類によってビニル重合も水索転移重合も可能である。転移重合での生成ポリマーの 結晶性は，Ca $(\mathrm{OR})_{2}$ を触媒上する采で最もすぐれたものが得られるが，この原因については今のところ不明 である。比較のためにメタクリル酸アミドについても種々の条件で重合を行ない類似の結果を得た。
\end{abstract}

\section{1. 緒言}

アクリル酸アミド(以下 AAm と略記)およびメタク リル酸アミド (MAAm) の塩基性触媒による水素転移重 合については, Breslow の最初の報告を初めとし ${ }^{1)}$ ，そ の後反応機構についての詳細な研究がある ${ }^{2), 3)}$ 。従来の 報告では使用している触媒は Grignard 試薬4) 以外は 第I族の金属およびそのアルコキシドである。

一般にイオン重合では触媒の酸・塩基性の強弱によっ て, 重合反応に著しい影響を受けることはよく知られて いる。それゆえ本報告では従来使用されている触媒より 塩基性が小さい II 族および III 族の金属アルコキシド とその他の化合物を触媒として重合を行ない，触媒の塩 基性と生成ポリマーの性質との関倸を検討した。この結 果, 極性溶媒を用いると III 族の金属まで水素転移重合 を起こす能力があり，無極性溶媒中では塩基性の小さい 触媒 $\left(\mathrm{Mg}(\mathrm{OR})_{2}, \mathrm{Al}(\mathrm{OR})_{3}\right)$ ではビニル重合物が得られ ることが明らかとなった。その他の重合条件と生成ポリ マーの性犋との関倸についても若干の検討を加えた。

\section{2. 実験}

\section{1 操 作}

重合はすべて前報と同しく四つロフラスコの中でかき まぜながら行なっだ)。アクリロニトリル (AN) の重合 は AAm と同様に行ない, 重合後水で泠却し, 冷塩酸を 溶媒と同量加えて 20 30 分かきませ，冷水に注入して 口過し, 希塩酸, 水, アルコール, エーテルの順に洗浄 した。またスチレンおよびメタクリル酸メチルの重合は ポリマーをメタノールで沈殿せしめることによって取り 出すこと以外は,すべて AAm と同様に行なった。 その他の操作もすべて前報と同様であり，生成ポリマ

* 京都大学工学部高分子化学教室(京都市左京区吉田本町)

** 日東紡績株式会社化学緎維研究所(福帛県安積郡富久山町)
一の構造の判定は赤外スペクトルによって, 分子量は 1 $\%$ キ酸溶液の $30^{\circ} \mathrm{C}$ での粘度数 $\left(\eta_{s p} / c\right)$ で比較した。

\section{2 実 験}

モノマーおよび溶媒は前報と同じく常法によって精製 した5)。

触媒のアルキコシドは $\mathrm{N}_{2}$ 気流中で四つロフラスコ中 で合成した。生石灰, 金属 $\mathrm{K}$ などの適当な文献記載の乾 燥剂で脱水 ${ }^{6)}$, 蒸留したアルコール $5 \sim 6 \mathrm{ml}$ に計算量の 金属を添加する。そのままで反応が進行しない場合は加 熱する。金属が溶解し終ったら末反応のアルコールを減 圧でできるだけ除去し，重合触媒として使用した。Al を 使用するときは反応前に金属面を洗浄し，塩化第二水銀 水溶液でアマルガムをつくってからアルコールと反応せ しめた。

Grignard 試薬は常法”によりェーテル中で合成し，こ れを注射器にて取り出して，そのまま触媒として使用し た。

アルキル亜鉛ハロゲン化物 (Blaise 試楽) も文献記載 の方法 ${ }^{8)}$ で合成し，未反応の亜鉛を沈殿分離した粘秷な 反応液を注射器で取り出して使用した。

\section{3. 結 果}

\section{1 重合形式と重合条件の関係}

\section{1 .1 触媒の重合能}

AAm および MAAm は Table 1 に示すような触媒 で重合することができる。Table 1 には収率と粘度数を 示した。第 II 属の金属アルコキシドはアルカリ金属の アルコキシドと触媒活性にあまり大きい差は認められな い。しかし Al およぴ Ti 化合物では重合速度は非常 に遅く, 特に $\mathrm{Ti}$ の場合はほとんど重合物は得られなか った。 $\mathrm{C}_{6} \mathrm{H}_{5} \mathrm{MgBr}$ および $\mathrm{C}_{2} \mathrm{H}_{5} \mathrm{ZnI}$ 触媒でも, 重合収率 は低いが比較的高重合度のものが得られた。

これらのポリマーの $\mathrm{KBr}$ 錠剂法による赤外吸収スペ 
Table 1. The polymerization of AAm and MAAm by various catalysts. $\left([M]_{0}: 1.41 \mathrm{~mol} / l\right.$ solvent, $[\mathrm{C}]: 1 / 30 \mathrm{~mol} / \mathrm{mol}$ monomer, Solvent : Xylene, [ $\beta$-Phenylnaphthyl amine]: $0.8 \mathrm{~g} / 100 \mathrm{ml}$ solvent)

(A) Polymerization of AAm.

\begin{tabular}{l|c|c|c|c|c}
\hline \hline \multicolumn{1}{c|}{ Catalyst } & $\begin{array}{c}\text { Temperature of } \\
\text { polymerization }\left({ }^{\circ} \mathrm{C}\right)\end{array}$ & $\begin{array}{c}\text { Time of poly- } \\
\text { merization }(\mathrm{hr})\end{array}$ & $\begin{array}{c}\text { Yield } \\
(\%)\end{array}$ & $\begin{array}{c}\text { Viscosity } \\
\text { number }\end{array}$ & $\begin{array}{c}\text { Type of resultant } \\
\text { polymer }^{\mathrm{b})}\end{array}$ \\
\hline $\mathrm{Mg}\left(\mathrm{OCH}_{3}\right)_{2}$ & 100 & 5 & 54 & 0.210 & $\mathrm{~V}$ \\
$\mathrm{Ca}\left(\mathrm{OC}_{2} \mathrm{H}_{5}\right)_{2}$ & 100 & 5 & 100 & 0.305 & $\mathrm{~T}$ \\
$\mathrm{Sr}\left(\mathrm{OC}_{2} \mathrm{H}_{5}\right)_{2}$ & 100 & 5 & 100 & 0.223 & $\mathrm{~T}$ \\
$\mathrm{Ba}\left(\mathrm{OC}_{2} \mathrm{H}_{5}\right)_{2}$ & 100 & 5 & 100 & 0.484 & $\mathrm{~T}$ \\
$\mathrm{Al}\left(\mathrm{O} i-\mathrm{C}_{3} \mathrm{H}_{7}\right)_{3}$ & 100 & 24 & 28 & 0.410 & $\mathrm{~T}$ \\
$\mathrm{Ti}\left(\mathrm{O} i-\mathrm{C}_{3} \mathrm{H}_{7}\right)_{3}$ & 100 & 24 & trace & - & - \\
$\mathrm{C}_{6} \mathrm{H}_{5} \mathrm{MgBr}{ }^{\mathrm{c})}$ & 70 & 5 & 64 & - & $\mathrm{T}$ \\
$\mathrm{C}_{2} \mathrm{H}_{5} \mathrm{ZnI}$ & 70 & 15 & 25 & 5.93 & $\mathrm{~V}$ \\
\hline
\end{tabular}

(B) Polymerization of MAAm.

\begin{tabular}{l|l|l|l|l|l|l}
\hline $\mathrm{Mg}\left(\mathrm{OCH}_{3}\right)_{2}$ & 100 & 10 & 76 & 0.125 & $\mathrm{~V}$ \\
$\mathrm{Ca}\left(\mathrm{OC}_{2} \mathrm{H}_{5}\right)_{2}$ & 100 & 10 & 54 & 0.087 & $\mathrm{~T}$ \\
$\mathrm{Sr}\left(\mathrm{OC}_{2} \mathrm{H}_{5}\right)_{2}$ & 100 & 10 & 87 & 0.060 & $\mathrm{~T}$ \\
$\mathrm{Ba}\left(\mathrm{OC}_{2} \mathrm{H}_{5}\right)_{2}$ & 100 & 10 & 98 & 0.083 & $\mathrm{~T}$ \\
$\left.\mathrm{C}_{6} \mathrm{H}_{5} \mathrm{MgBr}^{\mathrm{d}}\right)$ & 50 & 10 & 22 & 0.164 & $\mathrm{~V}$ \\
\hline
\end{tabular}

a) As $1 \%$ solutions in $98 \%$ formic acid

b) V: Vinyl type polymer, $\mathrm{T}$ : Transition polymer

c) Hydroquinone as inhibitor of radical polymerization

d) Hydroquinone as inhibitor of radical polymerization, Solvent: Dioxane, $[\mathrm{M}]_{0} 0.71 \mathrm{~mol} / l$ solvent

クトルは,すへて前報らにおいて報告した MAAm のラ ジカル重合物，あるいは RONa 触媒重合物のいずれか と類似の Amide の吸収を示した。すなわち AAm の 重合に㧍いては $\mathrm{Ca}, \mathrm{Sr}, \mathrm{Ba}, \mathrm{Al}$ アルコキシドおよび Grignard 試薬を触媒とする場合は, $6.5 \mu$ のトランスー モノ置換アミドの特性吸収交示した。その他の触媒では $6.5 \mu$ の吸收を示さず, ラジカル重合物とほとんど同一 の吸収を示した。本報告の表中ではピニル重合物を生ず る場合を $\mathrm{V}$, 転移重合物を生ずる場合を $\mathrm{T}$ で示すこと にする。

一方 MAAm もAAm と同様の触媒で重合する。Ca, $\mathrm{Sr}, \mathrm{Ba}$ のアルコキシド触媒で得たポリマーの赤外スペ クトルは, $6.5 \mu$ の強い吸収を示し, 水素転移重合をし ていることがわかる。一方 $\mathrm{Mg}\left(\mathrm{OC}_{2} \mathrm{H}_{5}\right)_{2}$ および $\mathrm{C}_{6} \mathrm{H}_{5}-$ $\mathrm{MgBr}$ 触媒の場合は, ラジカル重合物と同一の吸収(前 報, Fig. 6-a) を示し，6.5 の吸収は存在しない。し たがってこれらの触媒ではビニル重合物が得られること がわかる。

\section{1 .2 触媒およひ溶媒の影嘗}

Table 1 に示すように $\mathrm{Mg}\left(\mathrm{OCH}_{8}\right)_{2}$ 触媒では, AAm はキシレン溶媒中でビニル重合物を生じた。この点を明
らかにするために溶媒およびアルコキシドのアルキル基 の種類を変えて重合を行ない, 生成ポリマーの性質との 関係を検討した。Table 2 に生成ポリマーの構造, 収 率, 粘度数をまとめて示した。 $\mathrm{Mg}\left(\mathrm{OCH}_{3}\right)_{2}$ は無極性溶 媒中ではビニル化合物を生成し，クロルベンゼン中での み転移重合物を生成した。また $n$-ヘプタン中では $\mathrm{Mg}$ $\left(\mathrm{OC}_{2} \mathrm{H}_{5}\right)_{2}$ おうよび $\mathrm{Mg}\left(\mathrm{O} n-\mathrm{C}_{4} \mathrm{H}_{9}\right)_{2}$ 触媒の場合は, 転移 重合を示す $6.5 \mu$ の吸収が弱く存在する他はビニル重 合物とほとんど同じであって，ビニル重合物にわずかに 転移重合物が混在しているものと思われる。また一般に ビニル重合物は転移重合物に比して分子量が大きい傾向 にある。

$\mathrm{Al}(\mathrm{OR})_{3}$ 化合物についても同様に重合を行ない, 結果 をTable 2 にまとめて示した。傾向は $\mathrm{Mg}$ 化合物と似 ていて, $\mathrm{Al}\left(\mathrm{OCH}_{3}\right)_{3}$ ではいずれの溶媒中でもビニル重 合物を 生成するが， $\mathrm{Al}\left(\mathrm{OC}_{2} \mathrm{H}_{5}\right)_{3}$ は $n$-へプタン中では ビニル重合物，トルェン中では転移重合物がわずかに混 合したビニル重合物を生成した。

$\mathrm{Mg}\left(\mathrm{OCH}_{3}\right)_{2}$ 触媒によるビニル重合が，アニオン重合 かラジカル重合かについての知見を得るために，その他 のモノマーについての重合を行なった。Table 3 に示す 
Table 2. The effect of catalyst and solvent on type of polymerization.

$\left(\mathrm{Mg}(\mathrm{OR})_{2}\right.$ and $\mathrm{Al}(\mathrm{OR})_{3}$ catalyst, Polymerization temperature: $100^{\circ} \mathrm{C}$, Time of polymerization: $10 \mathrm{hr}$ for $\mathrm{Mg}(\mathrm{OR})_{2}, 20 \mathrm{hr}$ for $\mathrm{Al}(\mathrm{OR})_{3}$. Other conditions of polymerization are the same as those in Table 1.)

\begin{tabular}{|c|c|c|c|c|c|c|c|c|}
\hline Solvent & $n$-Hept & & Toluer & & Xyler & & Chlorober & zene \\
\hline \multirow{2}{*}{ Catalyst } & \multicolumn{2}{|c|}{ Type of polymer } & \multicolumn{2}{|c|}{ Type of polymer } & \multicolumn{2}{|c|}{ Type of polymer } & \multicolumn{2}{|c|}{ Type of polymer } \\
\hline & Yield (\%) & $\eta_{s p} / c$ & Yield (\%) & $\eta_{s p} / c$ & Yield (\%) & $\eta_{s p} / c$ & Yield (\%) & $\eta_{s p} / c$ \\
\hline \multirow{2}{*}{$\mathrm{Mg}\left(\mathrm{OCH}_{8}\right)_{2}$} & \multicolumn{2}{|l|}{$\mathrm{V}$} & \multicolumn{2}{|l|}{$\mathrm{V}$} & \multicolumn{2}{|l|}{$\mathrm{v}$} & \multicolumn{2}{|l|}{$\mathrm{T}$} \\
\hline & 5.6 & 3.72 & 54.0 & 3.57 & 62.7 & 0.210 & 60.5 & 0.066 \\
\hline \multirow{2}{*}{$\mathrm{Mg}\left(\mathrm{OC}_{2} \mathrm{H}_{5}\right)_{2}$} & \multicolumn{2}{|c|}{$\mathrm{V}_{+\mathrm{T}}$} & \multicolumn{2}{|l|}{$\mathrm{T}$} & \multicolumn{2}{|l|}{$\mathrm{T}$} & \multicolumn{2}{|l|}{$T$} \\
\hline & 19.9 & 1.27 & 84.3 & 0.176 & 68.1 & 0.183 & 60.3 & 0.095 \\
\hline \multirow{2}{*}{$\mathrm{Mg}\left(\mathrm{O} n-\mathrm{C}_{3} \mathrm{H}_{7}\right)_{2}$} & \multicolumn{2}{|l|}{$T$} & \multicolumn{2}{|l|}{$\mathrm{T}$} & \multicolumn{2}{|l|}{$\mathrm{T}$} & & \\
\hline & 87.0 & 0.195 & 90.2 & 0.076 & 60.4 & 0.141 & & \\
\hline \multirow{2}{*}{$\mathrm{Mg}\left(\mathrm{O} n-\mathrm{C}_{4} \mathrm{H}_{9}\right)_{2}$} & \multicolumn{2}{|c|}{$V_{+T}$} & \multicolumn{2}{|l|}{$\mathrm{T}$} & \multicolumn{2}{|l|}{$\mathrm{T}$} & & \\
\hline & 33.0 & 0.378 & 96.0 & 0.164 & 98.0 & 0.097 & & \\
\hline \multirow{2}{*}{$\mathrm{Al}\left(\mathrm{OCH}_{3}\right)_{8}$} & \multicolumn{2}{|l|}{$\mathrm{V}$} & \multicolumn{2}{|l|}{$\mathrm{V}$} & & & & \\
\hline & 4.2 & - & 10.5 & 1.42 & & & & \\
\hline \multirow{2}{*}{$\mathrm{Al}\left(\mathrm{OC}_{2} \mathrm{H}_{5}\right)_{3}$} & \multicolumn{2}{|l|}{$\mathrm{V}$} & \multicolumn{2}{|l|}{$\mathrm{V}_{+\mathrm{T}}$} & & & & \\
\hline & 10.8 & 3.89 & 94.0 & 1.26 & & & & \\
\hline \multirow{2}{*}{$\mathrm{Al}\left(\mathrm{O} i-\mathrm{C}_{3} \mathrm{H}_{7}\right)_{8}$} & & & \multicolumn{2}{|l|}{$\mathrm{T}$} & & & & \\
\hline & & & 27.6 & 0.412 & & & & \\
\hline
\end{tabular}

Table 3. Polymerization of some vinyl monomers by $\mathrm{Mg}\left(\mathrm{OCH}_{8}\right)_{2}$. ([Monomer]: $3 \mathrm{~mol} / l$, Solvent: Toluene, $\beta$-Phenylnaphthyl amine: $1 \mathrm{~g} / 100 \mathrm{~m} l$ solvent)

\begin{tabular}{c|c|c|c|c|c}
\hline \hline Monomer & $\begin{array}{c}{[\mathrm{C}]} \\
(\mathrm{mol} / l)\end{array}$ & $\begin{array}{c}\text { Temperature } \\
\left({ }^{\circ} \mathrm{C}\right)\end{array}$ & $\begin{array}{c}\text { Time } \\
(\mathrm{hr})\end{array}$ & $\begin{array}{c}\text { Yield } \\
(\%)\end{array}$ & $\begin{array}{c}{[\eta]\left(30^{\circ} \mathrm{C} \mathrm{DMF}\right)} \\
(100 \mathrm{~m} l / \mathrm{g})\end{array}$ \\
\hline AN & 0 & 75 & 10 & 0 & - \\
AN & 0.15 & $60 \sim 75$ & 10 & 12.4 & 0.049 \\
MMA & 0.15 & 100 & 24 & 0 & - \\
St & 0.15 & 100 & 24 & 0 & - \\
\hline
\end{tabular}

ようにここで行なった実験では AN のみがこの触媒で ポリマーを生成した。

\section{2 生成ポリマーの分子量}

前節で重合条件と重合形式の関倸についての結果を述 へた。次に転移重合を行なら采について重合条件と生成 ポリマーの粘度数の関倸を求めた。

触媒の種類を一定とした場合, たとえば Table 2 に 見られるよらに転移重合物の粘度数と用いた溶媒の種類 との間に一定の関係は見出されなかった。
次に溶媒を一定として, 典型的な転移重合触媒である $\mathrm{Na}$ および Ca アルコキシドを用いて AAm の重合を 行ない,アルキル基の影響を検即した。その結果は Fig. 1 に示すようにメタノールからプロパノールまでのアル コキシド(炭素数が 0 として $\mathrm{NaOH}, \mathrm{Ca}(\mathrm{OH})_{2}$ を含め て)では, アルコールの炭素数の增加につれて生成ポリ マーの分子量は大きくなるが，それ以上の高級アルコー ルのアルコキシドでは分子量は一定となる。Na アルコ キシドでは明りょらにこの関倸が成立するが，Ca アル 


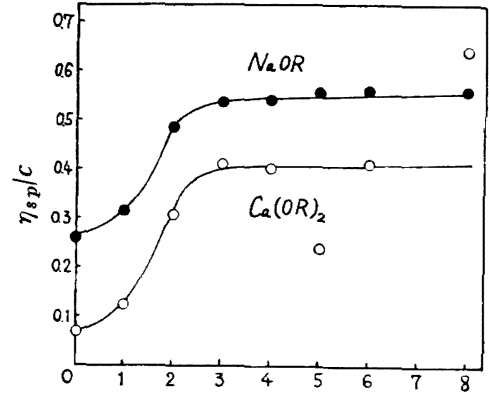

Number of C-atoms in alkyl group

Temperature of polymerization: $100^{\circ} \mathrm{C}$, Polymerization time: $5 \mathrm{hr}$, Polymer yield: ca. $100 \%$

Other conditions of polymerization are the same as in Table 1.

Fig. 1. Relationship between $\eta_{s p} / c$ of resultant polymer and the number of $\mathrm{C}$ atom in $\mathrm{R}$ group of $\mathrm{Na}$ and $\mathrm{Ca}$ alkoxide.

キシドではかなりばらついた結果が得られた。

また,アルコールの分枝の影響および金属の種類の影 侼 Table 4 に示した。Table 4 より見られるように a を除いては，アルコールの分枝が增すにつれて生成 !リマーの分子量が低下する。また金属の塩基性が低下 ・ると生成ポリマーの分子量は低下することが明らかと :った。

Table 4. The relationship between viscosity number of polymer and kind of catalyst.

(Conditions of polymerization are the same as those in Fig. 1., Polymer yield is almost $100 \%$ in all cases

\begin{tabular}{r|ccc|c}
\hline \hline $\begin{array}{l}\text { Metal } \rightarrow \\
\text { Ilcohol } \downarrow\end{array}$ & $\mathrm{Na}$ & $\mathrm{Ba}$ & $\mathrm{Ca}$ & $\mathrm{Mg}$ \\
\hline $\begin{array}{c}n-\mathrm{C}_{3} \mathrm{H}_{7} \mathrm{OH} \\
i-\mathrm{C}_{3} \mathrm{H}_{7} \mathrm{OH}\end{array}$ & 0.531 & 0.454 & 0.431 & 0.141 \\
\hline$n-\mathrm{C}_{4} \mathrm{H}_{9} \mathrm{OH}$ & 0.501 & 0.394 & 0.369 & - \\
$i-\mathrm{C}_{4} \mathrm{H}_{9} \mathrm{OH}$ & 0.619 & 0.402 & 0.396 & 0.097 \\
$t-\mathrm{C}_{4} \mathrm{H}_{9} \mathrm{OH}$ & 0.524 & 0.329 & 0.120 & - \\
\hline
\end{tabular}

\section{4. 考察}

AAm および MAAm はアニオン触媒で重合条件に って転移重合物あるいはビニル重合物を生成すること 明らかとなった。いずれの形式の重台が起こるかにつ ては, 主として触媒の塩基性に依存している。現在ま の得られた結果をまとめると Table 5 のようになる。 ible 5 には文献に示された結果もあわせて示した。明 かにアルコキシドでは金属の塩基性が大きい場合に転 重合物が生成している。この傾向は AAm も MAAm 同じであるが, Grignard 試薬, $\mathrm{Mg}(\mathrm{OR})_{2}$ などの結
Table 5. The relationship between the type of polymerization and metals of catalysts.

\begin{tabular}{c|c|c}
\hline \hline \multicolumn{1}{c|}{$\begin{array}{c}\text { Monomer } \rightarrow \\
\text { Catalyst } \downarrow\end{array}$} & AAm & MAAm \\
\hline LiOR $^{9)}$ & T & T \\
NaOR & T & T \\
KOR & T & T \\
$\mathrm{Mg}(\mathrm{OR})_{2}$ & T or V & V \\
$\mathrm{Ca}(\mathrm{OR})_{2}$ & $\mathrm{~T}$ & $\mathrm{~T}$ \\
$\mathrm{Ba}(\mathrm{OR})_{2}$ & $\mathrm{~T}$ & $\mathrm{~T}$ \\
$\mathrm{Sr}(\mathrm{OR})_{2}$ & $\mathrm{~T}$ & $\mathrm{~T}$ \\
$\mathrm{Al}(\mathrm{OR})_{3}$ & $\mathrm{~T} \mathrm{or} \mathrm{V}$ & - \\
$\mathrm{C}_{6} \mathrm{H}_{5} \mathrm{MgBr}$ & $\mathrm{T}$ & $\mathrm{V}$ \\
$\mathrm{C}_{2} \mathrm{H}_{5} \mathrm{ZnI}$ & $\mathrm{V}$ & - \\
\hline
\end{tabular}

果から見て MAAm の方がいくぶんビニル重合が起こ りやすいように思われる。

$\mathrm{Mg}(\mathrm{OR})_{2}$ によるビニル重合がアニオン機構によるも のか，ラジカル機構によるものか，今のところ明らかで ないが，溶媒のわずかの極性の差でこの両者のいずれも が相互に変化しらること，アニオン重合性の小さいスチ レンおよびメタクリル酸メチルは重合しないが，アニオ ン重合性の大きい AN が重合しやすいことなどからア ニオン機構によるものでないかと推定される。この推定 が正しいとすると, 対イオンの塩基性が强くなると (1) 式の右辺の形で重合が進行することが想像される。

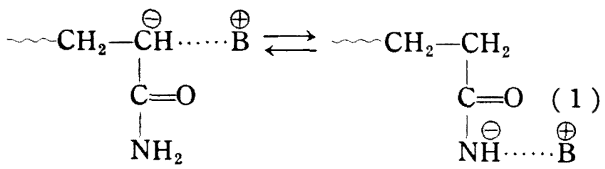

この関倸は対イオンが同一でも溶媒の誘電率が大きく なると転移重合が起こりやすくなるという Table 2 の 結果とも一致する。このように一つのモ, マーで反応の 形式が二つ以上あるとき, 重合条件によって両者の一方 を選ぶことができるのはジメチルケテンの重合などの例 で知られている。これら一連の反応では対イオンの性質 を変えることによって，重合形式を規定できる点で興味 深い。

同じ AAm の転移重合物でも $\mathrm{Ca}(\mathrm{OR})_{2}$ 触媒で得た 転移重合物は，X 線および偏光顕微鏡で見た結晶性は 他の触媒で得られたポリマーに比してすぐれている。純 粋の poly- $\beta$-alanine は結晶性が良いはずであるから， 実験的には確認していないが $\mathrm{Ca}(\mathrm{OR})_{2}$ 触媒で得た重合 物は副反応が少なくて転移重合のみが起こっているので あろう。

次に転移重合における触媒の分子量に対する影響を検 
討した。金属イオンの塩基性が大きいほど Table 4 に 示すように生成ポリマーの分子量が大となる。これは対 イオンの塩基性が大となると, 対イオンの付加による停 止反応が起こりにくいためと理解される。しかしアルコ ールの差による影響はこのような単純な対イオンの考え 方で説明されない。Fig. 1 に見られるように, $n$ ーアルキ ルアルコールでは炭素数の大きいものほど生成ポリマー の分子量は大きくなっている。すなわち、アルコキシド イオンの求核的性質が強いほど生成ポリマーの分子量が 大きくなる。このことは Table 4 のアルキル基が分枝 すると生成ポリマーの分子量が増加する傾向と一致して いる。

イオン重合では普通生成ポリマーの分子量は対イオン によって規定されると考えられている。そして AAm の転移重合では，開始反応は次の形であるとされてい $3^{3), 10)}$ 。ここで RO 基はポリマー末端に付加するこ

$$
\begin{aligned}
\mathrm{CH}_{2} & =\mathrm{CHCONH}_{2}+\mathrm{RO} \underset{\ominus}{\rightleftarrows} \mathrm{ROCH}_{2} \mathrm{CHCONH}_{2} \\
& \rightleftarrows \mathrm{ROCH}_{2} \mathrm{CH}_{2} \mathrm{CONH}
\end{aligned}
$$

とが確認されていて， RO 基が停止反応に関与すると 考えることができない。それゆえ，アルコキシドの種類 によって触媒の解離度が異なるか，対イオンが簡単な $($ metal $) \oplus$ の形でないことが考えられる。触媒は采に溶 解せず不均一であるため後者の可能性は十分にある。
以上 AAm および MAAm の重合について得られ† 実験結果を述べた。ビニル重合の機構, アルコキシドの 種類の分子量に対する影響の機構など不明であるが，重 合条件によってビニル重合と転移重合の両者の起こり? ることを明らかにした。

付記：本研究は 1962 年 4 月, 日本化学会第 15 年会で 表した。

$$
\text { 文献 }
$$

1) D. S. Breslow, G. E. Hulse, A.S. Matlack: J Am. Chem. Soc., 79, 3760(1957)

2) N. Ogata: Bull. Chem. Soc., Japan, 33, 90 (1960)

3) N. Ogata: Makromol. Chem., 40, 55(1960)

4) N. Ogata: J. Polymer Sci., 46, 271(1960)

5）岡村誠三, 大石良季, 東村敏延, 妹尾忠雄: 高化 19, 323(1962)

6）桑田 勉：「溶凨」(1953)(丸善)記載の方法によ一 た。

7) 日本化学会編：「実験化学講座」, 20-II, 102(1961 丸善

8) 日本化学会編：「実験化学講座」, 20-II, 130(1961 丸善

9）谷 久也, 武田順一：繊維化学研究所年報, 13 134(1960)

10）谷 久也, 小国信樹：繊維化学研究所年報, 15 152(1962)

\title{
The Effect of Catalysts and Solvents on the Transition Polymerization of Acrylamide
}

\author{
By Seizo Okamura*, Toshinobu Higashimura* and \\ Tadao Seno-o**
}

\begin{abstract}
Acrylamide was polymerized by metal (group I, II and III) alkoxides, $\mathrm{RMgX}$ and $\mathrm{RZnX}$ in the presence of an inhibitor of the radical polymerization at about $100^{\circ} \mathrm{C}$. When a strong base was used as a catalyst, the poly- $\beta$-alanine was produced by the transition polymerization. On the other hand by a weak basic catalyst, the vinyl polymerization was recognized. For example, when $\mathrm{Mg}(\mathrm{OR})_{2}$ was used as a catalyst, the vinyl polymerization as well as the transition polymerization proceeded dependeng on the kinds of solvent and $R$ of catalysts. Poly-, 3 -alanine obtained by $\mathrm{Ca}(\mathrm{OR})_{2}$ was more crystalline than any other polymers, but the reason cannot be interpreted now. Similar results were recognized on the polymerization of methacrylamide by basic catalysts.
\end{abstract}

* Department of Polymer Chemistry, Faculty of Engineering, Kyoto University (Yoshida, Sakyo-ku, Kyoto)

** Research Laboratory for Chemical Fibers, Nitto Boseki Co. Ltd. (Fukuyama, Asaka-gun, Fukushima) 